\title{
Strategi Regulasi Diri dalam Peningkatan Motivasi Membaca
}

\author{
Vismaia Sabariah Damaianti \\ vismaia@upi.edu \\ Universitas Pendidikan Indonesia, Jalan Dr. Setiabudhi No. 229, Bandung, Indonesia
}

\begin{abstract}
Abstrak. Era adaptasi di masa pandemi COVID-19 ini dapat menjadi momen bagi kita untuk mulai berpikir bagaimana membuat perubahan pendidikan di masa depan. Para siswa memerlukan kemampuan yang relevan dalam menghadapi perubahan dan mengatasi tantangan, di antaranya dengan kemampuan membaca. Kemampuan membaca semakin dipentingkan ketika masyarakat bergerak semakin dinamis, berkebutuhan semakin kompleks, berpikir semakin kritis, dan bernilai semakin tinggi. Kemampuan membaca yang tinggi dapat dicapai apabila ada kondisi yang menggerakkan pembelajar untuk mencapai kemampuan membaca tersebut. Motivasi membaca dapat menyebabkan timbulnya kekuatan pada individu untuk menggerakkan seseorang melaksanakan kegiatan membaca. Self-regulated learning dapat menjadi salah satu alternatif pembelajaran agar motivasi dapat meningkat dalam suasana belajar mandiri. Hasil studi menunjukkan bahwa self regulated learning relevan digunakan untuk memantik motivasi akademik siswa. Regulasi diri dalam belajar juga membawa siswa menjadi master (ahli/menguasai) dalam belajarnya. Self regulated learning melibatkan tiga komponen utama: strategi kognitif, strategi metakognitif, dan motivasi. Ada hal penting yang perlu mendapatkan perhatian atas keberhasilan proses peningkatan motivasi membaca, yaitu persistensi. Keberhasilan dari proses motivasi adalah adanya persistensi yang tinggi. Adanya hambatan dan tantangan membaca dapat diatasi dengan persistensi yang tinggi.
\end{abstract}

Kata kunci: motivasi membaca, persistensi, self regulated learning

\section{Pendahuluan}

Pandemi COVID-19 telah menyebar ke semua negara hanya dalam waktu beberapa bulan. Pandemi ini memaksa warga dunia melakukan banyak intervensi, seperti kesehatan, sosial, ekonomi, budaya, politik, juga pendidikan. Warga belajar menjadi populasi yang terdampak secara signifikan. Pelarangan interaksi dengan intensitas tinggi, seperti di persekolahan menyebabkan sulitnya pelaksanaan proses pembelajaran yang berujung pada pembatasan kegiatan di sekolah.

Tantangan baru akan muncul dengan diberlakukannya pembatasan interaksi antarwarga belajar. Beragam studi menunjukkan bahwa paparan tekanan akan muncul dan mengganggu proses pembelajaran dan perkembangan siswa di masa depan. Pembelajaran jarak jauh dapat meminimalisasi risiko penularan. Akan tetapi, untuk waktu yang lama dampak positif dari pembelajaran jarak jauh itu tidak dapat berdampak dengan baik lagi.

Era adaptasi kebiasaan baru (new normal) dapat menjadi momen bagi kita untuk mulai berpikir bagaimana membuat perubahan pendidikan di masa depan. Para siswa memerlukan kemampuan yang relevan dalam menghadapi perubahan dan mengatasi tantangan. Salah satu yang dapat dilakukan adalah dengan membekali siswa agar tanggap terhadap informasi, cerdik dalam mengolah informasi, dan piawai dalam memanfaatkan informasi untuk kepentingan kehidupannya. Salah satu upaya yang dapat dilakukan adalah dengan meningkatkan kemampuan dan motivasi membaca siswa.

Kemampuan membaca semakin dipentingkan ketika masyarakat bergerak semakin dinamis, berkebutuhan semakin kompleks, berpikir semakin kritis, dan bernilai semakin tinggi. Seiring dengan kemajuan teknologi dan informasi, semakin banyak tuntutan dari proses kehidupan manusia yang memerlukan kemampuan untuk tanggap informasi, cerdik dalam mengolah informasi, dan piawai dalam mengelola informasi. Dengan kemampuan membaca seseorang akan terampil dalam menghadapi tantangan di era informasi ini. 
Dengan kemampuan membaca yang baik seseorang akan terampil melakukan kegiatan sehari-hari dari yang dianggap remeh sampai kegiatan penting untuk kelangsungan kehidupan yang beradab. Orang tua harus mampu menafsirkan informasi kontraindikasi konsumsi obat untuk anaknya. Pengguna gawai mustahil tidak terampil mengisi aplikasi. Pekerja yang bergaji baik harus tanggap terhadap peluang. Atasan yang sukses harus piawai mengelola memo dan mengkaji laporan. Periset yang unggul harus terampil mengefektifkan waktu dalam menyerap ilmu dan mereaksi perubahan. Pendakwah yang benar harus cerdik dalam mengkaji informasi atas kebenaran dan ketetapan.

Beberapa ahli menyampaikan pentingnya kemampuan membaca. Watkins (2018) menyatakan kemampuan membaca adalah pencapaian manusia yang luar biasa karena dia dapat menyaksikan dibuatnya sejarah, bisa menghasilkan pengetahuan baru, dan mampu menjangkau orang yang terpisah jarak dan waktu.

Kemampuan membaca merupakan kenikmatan yang dapat diperoleh manusia sepanjang hidupnya. Dengan keterampilan membaca seseorang dapat melakukan perjalanan dari rumah ke alam impian, dapat melarikan diri untuk mendapatkan kesenangan (Spears, 2013). Dengan membaca, seseorang dapat pergi ke mana saja bisa menjadi apa saja. Bisa memperoleh kemungkinan yang tidak terbatas.

Selanjutnya membaca itu penting karena dapat mengembangkan pikiran. Pikir adalah otot yang memerlukan latihan. Membaca dengan memahami kata-kata tertulis adalah salah satu cara berlatih untuk menumbuhkan kemampuan berpikir (Davis, 2016). Tentunya kemampuan berpikir dapat digunakan seseorang untuk belajar, bertanya, dan untuk memahami berbagai masalah penting.

Lebih dalam lagi Harris \& Sipay (1980) menyatakan bahwa kecakapan membaca sangat penting dimiliki individu apabila dia tak ingin kehilangan harga diri dan kesejahteraan hidupnya. Membaca adalah hal mendasar dalam mengembangkan citra diri yang baik. Seseorang yang kemampuan membacanya rendah sering memandang rendah tentang diri kemampuan mereka sendiri. Sering sekali dia merasa seolah dunia menentang dan mengisolasi dirinya. Sebaliknya, orang yang tidak memiliki keterampilan membaca bagaikan terkena batu sandungan. Apabila seseorang terhambat membaca maka kemampuan lain akan terhambat pula (Hoyt, 1950).

Banyak faktor yang mempengaruhi kemampuan membaca seorang individu. Motivasi membaca selama ini dianggap sebagai faktor yang paling penting dalam upaya menciptakan individu yang gemar dan berhasil dalam membaca. Motivasi membaca dipandang sebagai internalisasi tujuan-tujuan yang menghasilkan kemampuan efektif membaca (Pintrich \& Schrauben, 1992). Dalam pandangan ini, motivasi membaca dapat dianggap sebagai dasar-dasar pemikiran untuk mencapai kegiatan membaca yang berhasil. Motivasi yang tinggi untuk mencapai keberhasilan dalam membaca merupakan faktor yang menentukan dalam keberhasilan membaca (Anderson \& Pearson, 1984).

Finn dan Cox (1992) membuktikan bahwa siswa yang memiliki motivasi yang tinggi cenderung memiliki skor kemampuan membaca yang lebih tinggi daripada siswa yang kurang memiliki motivasi membaca. Hal ini dapat dijelaskan melalui kaitan antara motivasi membaca, frekuensi membaca, dan kemampuan membaca (Wiegfield \& Guthrie, 1996). Anak-anak yang memiliki motivasi membaca akan lebih sering membaca dan akan meningkatkan jumlah materi yang dibaca (Cox \& Guthrie, 2001). Adapun frekuensi membaca sangat berkaitan dengan peningkatan kemampuan memahami bacaan (Guthrie \& Wiegfield, 2000). Dengan frekuensi membaca yang tinggi seseorang dapat mengembangkan keterampilan kognitif yang diperlukan dalam mendapatkan kemampuan memahami bacaan. Dengan banyak membaca seseorang dapat 
memperluas pemahaman kosa kata dan mengembangkan strategi membaca. Faktor-faktor tersebut diperlukan untuk pemahaman membaca yang baik.

Menurut Pintrich dan Schrauben (1992) motivasi membaca dapat berarti suatu dorongan untuk mencapai tujuan membaca. Motivasi timbul pada diri seseorang karena adanya dorongan untuk memperoleh kepuasan hidup. Salah satu cara untuk mencapai kepuasan itu adalah menyerap informasi yang diperlukan dari berbagai bahan bacaan. Seseorang yang memiliki motivasi membaca yang tinggi mempunyai hasrat yang kuat untuk mendapatan informasi dalam wacana dan menghayati pentingnya arti wacana bagi dirinya. Dengan adanya motivasi membaca, seseorang mempunyai kecenderungan untuk melakukan kegiatan membaca dengan tujuan memperoleh kepuasan menemukan informasi.

Motivasi dalam kegiatan membaca ini juga penting karena degan motivasi seorang pembaca akan memerlukan perasaan berkompeten. Deci (1991) berpendapat motivasi yang tinggi menghasilkan tingkah laku yang menyebabkan individu berkompeten. Dengan motivasi membaca seseorang dapat mengatasi tantangan dan mampu meningkatkan Tingkah laku yang dihasilkan oleh motivasi yang tinggi itu terdiri atas dua bentuk tingkah laku, yakini tingkah laku yang ditujukan pada upaya peningkatan stimulasi dan tingkah laku yang ditujukan pada upaya mengatasi situasi-situasi atau tantangan-tantangan. Hal ini diperkuat oleh pendapat Artino dan Stephens (2009) bahwa motivasi diperlukan dalam pemahaman membaca teks-teks yang menantang.

Selanjutnya ditekankannya pula bahwa seorang individu akan melibatkan pembuatan pilihan atau keputusan dalam bertingkah lakunya. Keputusan itu didasarkan atas informasiinformasi yang tersedia dalam lingkungannya maupun atas dasar ingatan, sikap, dan perasaannya sendiri. Individu yang membuat pilihan untuk mencapai tujuannya berdasarkan ingatan, sikap, dan perasaannya sendiri adalah individu yang memiliki motivasi tinggi.

Upaya untuk meningkatkan kemampuan membaca sangat perlu dilakukan. Masyarakat Indonesia, khususnya pembelajar memerlukan kemampuan membaca untuk merealisasikan kebutuhannya hidupnya dan untuk mewujudkan keberhasilan pendidikannya. Akan tetapi, tingkat kemampuan membaca pembelajar di Indonesia masih menjadi masalah yang memprihatinkan. Daya baca siswa Indonesia berdasarkan penilaian PISA (2018) meraih nilai 371 sedangkan nilai tertinggi dicapai Cina sebesar 555. Ini menempatkan posisi daya baca anak Indonesia di peringkat 72 dari 77 negara yang dinilai Kompas, 2019). Kondisi ini memerlukan upaya serius, terutama upaya yang dilakukan dalam konteks pembelajaran.

Selain isu rendahnya kemampuan membaca, kemandirian dan kebebasan dalam proses pembelajaran menjadi isu penting setakat ini. Berkembangnya ilmu pengetahuan dan teknologi memungkinkan pembelajar berkesempatan belajar dengan lebih bebas dan mandiri. Tentunya kemandirian dan kebebasan yang dimiliki siswa harus diarahkan sehingga tujuan pendidikan yang baik dapat dicapai. Pemerintah Indonesia menyatakan bahwa Pendidikan Nasional abad ke-21 bertujuan menghasilkan sumber daya manusia yang berkualitas, yaitu yang berkepribadian mandiri dan berkemauan untuk mewujudkan cita-cita bangsanya (BSNP, 2010).

Kemampuan membaca yang tinggi dapat dicapai apabila ada kondisi yang menggerakkan pembelajar untuk mencapai kemampuan membaca tersebut. Motivasi membaca dapat menyebabkan timbulnya kekuatan pada individu untuk melaksanakan kegiatan membaca. Adapun pembelajaran mandiri bisa dilakukan melalui strategi pengelolaan diri dalam belajar. Oleh karena itu, perlu dirumuskan alternatif strategi pembelajaran yang dapat meningkatkan kemampuan dan motivasi membaca siswa. 
Latar belakang tersebut mendorong penulis untuk melakukan pembahasan yang berkaitan dengan Self-regulated learning sebagai alternatif strategi pembelajaran untuk meningkatkan kemampuan membaca dan motivasi siswa selama pembelajaran jarak jauh. Berdasarkan hal tersebut, rumusan permasalahan pada pembahasan ini antara lain: (1) Bagaimanakah implementasi peningkatan motivasi membaca melalui Self Regulated Learning? (2) Bagaimanakah bentuk strategi yang dapat digunakan untuk meningkatkan motivasi membaca melalui Self Regulated Learning? (3) Faktor apakah yang berpengaruh terhadap peningkatan motivasi membaca dalam Self Regulated Learning?

Untuk menjawab rumusan masalah tersebut, penulis melakukan kajian terhadap berbagai teori yang berkaitan dengan konsep membaca, motivasi membaca, dan Self Regulated Learning. Selain itu, pembahasan juga dilakukan terhadap penelitian-penelitian relevan berkaitan dengan variabel-variabel yang telah disebutkan sebelumnya.

\section{Hasil dan Pembahasan}

\section{Implementasi Peningkatan Motivasi Membaca melalui Self Regulated Learning}

Self-regulated learning dapat menjadi salah satu alternatif pembelajaran agar motivasi dapat meningkat dalam suasana belajar mandiri. Hasil studi menunjukkan bahwa Self regulated learning memiliki efek positif dan signifikan pada motivasi akademik (Lavasani, M.G dkk., 2011). Temuan penelitian ini sejalan dengan peneliti lain, seperti Schober \& Ziegler (2001), Fuchs et al (2003), Schunk (1996). Berdasarkan apa yang ditemukan Pintrich (2000) dan Zimmerman (2000) terbukti pula bahwa, siswa dengan keterampilan pengaturan diri (self-regulation skills) lebih termotivasi dalam hal keberhasilan akademik dan belajar lebih baik daripada siswa lain.

Zimmerman \& Martinez-Pons (2001) mendefinisikan self regulated learning sebagai tingkatan ketika siswa secara aktif melibatkan metakognisi, motivasi, dan perilaku dalam proses belajar. Self regulated learning juga didefinisikan sebagai bentuk belajar individual yang secara otonomi mengembangkan pengukuran (kognisi, metakognisi, dan perilaku), dan memonitor kemajuan belajarnya dalam meningkatkan motivasi (Baumert et al., 2002).

Self regulated learning dipilih sebagai kerangka konsep pembelajaran yang beselaras dengan pembelajaran mandiri. Pembelajar dengan self regulated learning mampu mengatur waktu belajar mereka sendiri, mencari informasi tentang pengetahuan dan materi pembelajaran dari berbagai sumber, yaitu guru di sekolah dan sarana media dan teknologi yang ada (Zimmerman, 2008). Self regulated learning ini membantu pembelajar dalam mengarahkan mereka pada kemandirian belajar, yaitu mengatur jadwal belajar, menetapkan target belajar, dan mencari informasi yang dibutuhkan secara mandiri. Self regulated learning menekankan pentingnya tanggung jawab personal dan mengontrol pengetahuan dan keterampilan yang diperoleh. Regulasi diri dalam belajar juga membawa siswa menjadi master (ahli/menguasai) dalam belajarnya. Perspektif self regulated learning dalam belajar dan prestasi siswa tidak sekedar istimewa (disctintive) tetapi juga berimplikasi pada bagaimana seharusnya guru berinteraksi dengan siswa, serta bagaimana seharusnya sekolah diorganisasikan (Zimmerman, 1990).

Self regulated learning melibatkan tiga komponen utama: strategi kognitif, strategi metakognitif, dan motivasi (Schraw, Crippen, \& Hartley, 2006). Sejalan dengan pendapat Schraw dkk. (1998), Pintrich mengembangkan model pembelajaran berbasis self regulated learning melalui strategi kognitif dan strategi metakognitif. 
Kognisi mencakup keterampilan yang diperlukan untuk menyandikan, meningkatkan ingatan, dan menghafalkan informasi. Metakognisi mencakup keterampilan yang memungkinkan peserta didik memahami dan memantau proses kognitif mereka. Motivasi mencakup keyakinan dan sikap yang dipengaruhi oleh penggunaan dan pengembangan keterampilan kognitif dan metakognitif. Peran ketiga komponen dalam self regulated learning tersebut dapat dijelaskan seperti berikut.

\section{Strategi Kognitif dan Metakognitif dalam Self Regulated Learning}

Ketika seseorang termotivasi untuk membaca dalam waktu yang lama maka sebenarnya ia selalu menggunakan pemahamannya atas materi teks yang dibaca. Keterlibatan kognitif dalam kegiatan membaca mengarah pada penyiapan aspek-aspek kognitif membaca agar diperoleh rasa berkompeten dalam memahami bacaan. Keyakinan akan kompetensi membaca ini akan mendorong seseorang untuk membaca.

Strategi kognitif dilakukan dalam kegiatan (1) pengulangan, (2) elaborasi dan (3) pengorganisasian (Purdie, 2002).

1. Strategi Pengulangan. Dalam pembelajaran membaca strategi pengulangan dilakukan melalui pengulangan membaca kata-kata atau informasi yang dibaca dan menggarisbawahi bagian-bagian penting dalam sebuah teks.

2. Strategi elaboratif. Strategi ini dilakukan melalui encoding informasi yang dilakukan dengan menghubungkan informasi baru dari teks dengan informasi yang telah disimpan dalam skemata.

3. Strategi pengorganisasian. Dalam kegiatan membaca, strategi ini merupakan upaya membuat struktur informasi. Kegiatan dilakukan dilakukan dengan membuat catatan penting, menggarisbawahi ide pokok bacaan, membuat mind maping gagasan dari suatu bacaan.

Selain kognisi, metakognisi merupakan faktor yang dapat memperkuat motivasi seseorang dalam membaca. Seperti yang dinyatakan Spörer, et.al. (2009) bahwa membaca sebagai aktivitas multikomponen tidak hanya memerlukan kognisi, tetapi juga metakognisi untuk menyelidiki proses membaca secara komprehensif. Metakognisi didefinisikan sebagai kesadaran dan pemantauan pikiran dan kinerja seseorang (Schraw, 1998). Metakognitif merupakan suatu bentuk kemampuan melihat diri sendiri sehingga apa dilakukan dapat terkontrol secara optimal.

Schraw (1998) menyatakan bahwa metakognisi terdiri atas dua komponen utama, yaitu (1) pengetahuan metakognitif dan (2) regulasi metakognitif. Pengetahuan metakognitif mengacu pada pengetahuan tentang kognisi, yang berarti bahwa apa yang diketahui individu tentang kognisi mereka sendiri atau tentang kognisi secara umum. Adapun regulasi metakognitif merupakan serangkaian kegiatan yang mengendalikan pikiran dan kegiatan belajar peserta didik, termasuk perencanaan, monitoring, dan evaluasi (Schraw \& Dennison, 1994).

1. Tahap perencanaan pada pembelajaran membaca dilakukan melalui kegiatan meninjau informasi tugas yang harus diselesaikan

2. Tahap monitoring diri dilakukan pemeriksaan kemajuan diri, seperti penyelesaian tugas, memantau kadar pemahaman dan kemajuan dalam penyelesaian tugas.

3. Adapun tahap evaluasi dilakukan dengan cara menilai dan mengevaluasi diri dalam menghadapi tugas. (Brown et al dalam Flavell dan Markman (eds.), 1983).

Melalui metakognitif, kedewasaan dan kemandirian dalam belajar dapat diasah. Ketika peserta didik mampu merancang, memantau, dan merefleksikan proses belajar mereka secara sadar, sehingga mereka akan menjadi lebih percaya diri dalam belajar. Kepercayaan diri ini akan meningkatkan motivasi belajar. 


\section{Persistensi sebagai Keberhasilan Proses Motivasi Membaca}

Pembelajaran dengan strategi regulasi diri atau Self-regulated learning dipilih karena dapat menjadi salah satu alternatif pembelajaran agar motivasi membaca siswa dapat meningkat dalam suasana belajar mandiri. Beberapa hasil studi para ahli membuktikan bahwa self regulated learning memiliki efek positif dan signifikan pada motivasi akademik. Dengan keterampilan pengaturan diri siswa lebih termotivasi untuk belajar lebih baik dalam mencapai keberhasilan akademiknya.

Selanjutnya, ada hal penting yang perlu mendapatkan perhatian atas keberhasilan proses peningkatan motivasi, dalam hal ini motivasi membaca, yaitu persistensi. Hubungan Strategi Regulasi Diri, Motivasi, dan Persistensi dapat terlihat pada gambar di bawah ini.

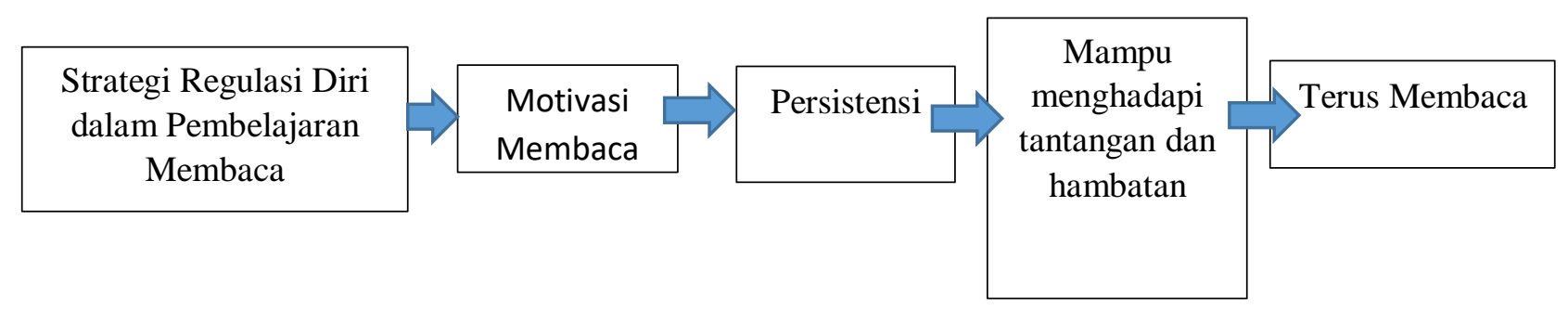

Gambar1. Pengaruh Strategi Regulasi Diri terhadap Motivasi Membaca

Huitt (1999) menjelaskan bahwa para siswa yang memiliki motivasi untuk meraih tujuan yang lebih baik adalah mereka akan memiliki persistensi yang lebih baik dalam belajar. Persistensi adalah ketahanan diri seseorang dalam melaksanakan komitmen awalnya. Dengan persistensi yang tinggi, siswa akan bertahan melakukan kegiatan membaca walaupun ada tantangan dan gangguan yang ada di hadapannya.

\section{Simpulan}

Self-regulated learning dapat menjadi salah satu alternatif pembelajaran agar motivasi membaca siswa dapat meningkat dalam suasana belajar mandiri. Self regulated learning melibatkan komponen strategi kognitif dan strategi metakognitif. Kognisi mencakup keterampilan yang diperlukan untuk menyandikan, meningkatkan ingatan, dan menghafalkan informasi. Metakognisi mencakup keterampilan yang memungkinkan peserta didik memahami dan memantau proses kognitif mereka. Keberhasilan dari proses motivasi adalah adanya persistensi yang tinggi. Adanya hambatan dan tantangan, membaca dapat diatasi dengan persistensi yang tinggi.

Berdasarkan simpulan tersebut, guru dan pihak terkait di sekolah dapat mengimplementasikan strategi Self regulated learning sebagai upaya untuk meningkatkan kemampuan dan motivasi membaca siswa. Adapun untuk mengetahui keterpakaian strategi Self regulated learning yang telah diimplementasikan pada siswa, dapat dilakukan uji efektivitas dengan melibatkan kelas eksperimen dan kelas kontrol.

\section{Daftar Pustaka}

Artino Jr. A.R. \& Stephens, J. M. 2009. Academic motivation and self-regulation: A comparative analysis of undergraduate and graduate students learning online. Internet and Higher Education, 12, 146-151. 
Anderson, R.C., \& Pearson, P.D. 1984. A schema- theoretic view of reading. In P.D. Pearson, M. Kamil, P. Mosenthal, \& R. Barr (Eds.), Handbook of reading research (vol. 1, pp. 255-291). New York: Longman.

BSNP 2010. Paradigma Pendidikan Nasional di Abad 21. Jakarta: BNSP

Baumert et al.2002 Self Regulated Learning as Cross Cultral Concept. Diakses dari http://www.mpibberlin.mpg.de/pisa/pdfs/ccengl.pdf

Cox, K.e., \& Guthrie, J.T. 2001. Motivational and Cognitive Contributors to Students' Ammount of Reading. Contemporary Educational Psychology 26, 116-131

Davis, G. 2016. Why is Reading Important? https://www.learn-to-read-princegeorge.com/why-is-reading-important.html

Deci, E.L .1991. "The Relation of Interest to Motivation of Behavior: A Sel-Determination Theory Perspective. Hillsdale, NY: Lawrence Erlbawn.

Flavell, J.H. \& Markaman, E. (volume eds.) 1983 in Mussen, P. (gen. ed.) Handbook of Child Psychology, Vol.III, Cognitive Development, New York: John Wiley \& Sons.

Finn, J.D. \& Cox, D, .1992. Participation and Withdrawal Among Fourth-Grade Pupils. American Educational Research Journal, 29. 141-163

Fuchs, L. S., Fuchs, D., Prentice, K., Burch, M., Hamlett, C. L., Owen, R., et al. 2003. Explicitly teaching for transfer: Effects onthird-grade students' mathematical problem solving. Journal of Educational Psychology, 95(2), 293-305

Guthrie, J. T., \& Wigfield, A. 2000. Engagement and motivation in reading. In M. L. Kamil, P. B. Mosenthal, P. D. Pearson, \& R. Barr (Eds.), Handbook of reading research (Vol. 3, pp. 403422). Mahwah, NJ: Erlbaum.

Harris, J.A., \& Sipay, E.R. 1980. Hoe to Increase Reading Ability. London: Longman.

Hoyt, L. (1950). Revisit, Reflect, Retell: Strategies for Improving Reading Comprehension. NY: Heinemann

Huitt, W. 1999. Conation as an important factor of mind. [Online] URL: http://chiron.valdosta.edu/whuitt/col/regsys/conation.html

Kompas .2019. https://edukasi.kompas.com/read/2019/12/07/09141971/daftar-lengkap-skorpisa-2018-kemampuan-baca-berapa-skor-indonesia?page $=$ all

Lavasani, M.G., Mirhosseini,F.S., \& Hejazi, E., \& Davoodi, M. $2011 . \quad$ The Effect of Self-regulation Learning Strategies Training on the Academic Motivation and Self-efficacy . Procedia and Behavioral Sciences, 29 (627-632)

Pintrich, P.R., \& Schrauben .1992. Student's Motivational Beliefs and Their Cognitive Engagement in Classroom Academic Tasks Hillsdale: Erlbaum

Pintrich, PR. 2000. The role of goal-orientation in self-regulated learning. In: Handbook of self-regulation. Edited by M. Boekaerts, PR. Pintrich, \& M. Zeidner. San Diego, CA: Academic Press: 451-502

PISA .2018. Reading Literacy Framework https://www.iprase.tn.it/documents/ 20178/344196/Pisa+2018+reading+literacy+framework+_final.pdf/14f3abfc-966c46b1-a8d8-4d962193ecfd

Purdie, dkk., 2002. A Review of the Research on Interventions for Attention Deficit Hyperactivity Disorder: What Works Best? Review of Educational Research, hal. 87

Schraw G. 1998. Promoting general metacognitive awareness. Instructional Science 26: 113125.

Schraw, G., \& Dennison, R. S. 1994. Assessing metacognitive awareness. Contemporary Educational Psychology, 19, 460-475. 
Schraw, G., Crippen, K.J., \& Hartley, K. 2006. Promoting Self-Regulation in Science Education: Metacognition as Part of a Broader Perspective on Learning. Research in Science Education .2006. 36: 111-139DOI: 10.1007/s11165-005-3917-8

Schober, B., \& Ziegler, A. 2001. Das M“ unchner Motivations training (MMT): Theoretischer Hintergrund, $\mathrm{F}^{*}$ orderziele und exemplarische Umsetzung (The Munich motivational training: Theoretical background, aims and a first evaluation). Zeitschrift f'ur P"adagogische Psychologie, 15(34), 168-180.

Schunk, D. (1996). Goal and self-evaluative influences during children's cognitive skill learning. American Educational Research Journal, 33(2), 359-382.

Spears, D. 2013. Improving Reading Skills.NY: McGraw-Hill Companies.

Spörer, N., Brunstein, J. C., \& Kieschke, U. L. F. 2009. Improving students' reading comprehension skills: Effects of strategy instruction and reciprocal teaching. Learning and instruction, 19(3), 272-286.

Watkins, P. 2018.Teaching and Developing Reading Skills: Cambridge Handbooks for Language Teachers. UK: Cambridge University Press

Wiegfield, A. \& Guthrie, J. 1996. Growth of Literacy Engagement: Changes in Motivations and strategies During Concept-Oriented Reading Instruction. Reading Research

Zimmerman, B.J. 2000. Attainment of self-regulation: A social cognitive perspective. In M. Boekaerts, P. Pintrich, \& M. Zeidner (Eds.), Handbook of self-regulation (pp. 13-39). Orlando, FL: Academic Press

Zimmerman, B.J. \& Martinez-Pons, M., .2001. Students Differences in Self Regulated Learning: Relating Grade, Sex, and Giftedness to Self Efficacy and Strategy Use. Journal of Educational Psychology. 82 (1), 51-59.

Zimmerman, . 2008 . Investigating Self-Regulation and Motivation: Historical Background, Methodological Developments, and Future Prospects. American Educational Research Journal, 45(1): 166-183, (Online) 